\title{
Modulation of cholinergic contractions of airway smooth muscle by cathinone: potential beneficial effects in airway diseases
}

\author{
V.C. Freund-Michel*, M.A. Birrell*, H.J. Patel*, I.M. Murray-Lyon" and M.G. Belvisi*
}

ABSTRACT: Infusion of khat leaves is an African traditional remedy used to treat airway diseases. The beneficial effects of khat are thought to be due to the activity of its main active component, cathinone.

Cathinone inhibited electric field stimulation-induced acetylcholine release and the contractions of smooth muscle, which could be responsible for the beneficial effects seen in airway disease. The mechanism of action of this natural product appears to be via the activation of both pre-junctional $\alpha_{2}$ adrenergic and 5-hydroxytryptamine 7 receptors.

The present novel study describes how cathinone modulates airway tone, and may go some way to explaining the traditional use of khat as a remedy for the alleviation of respiratory disease symptoms.

In conclusion, cathinone may have beneficial effects in airway diseases with heightened cholinergic tone. There is some rationale for follow-up of these observations, given previous experience of other traditional remedies being developed for therapeutic use.

KEYWORDS: Anticholinergic therapies, cathinone, chronic obstructive pulmonary disease, parasympathetic innervation

$\mathbf{K}$ hat (Catha edulis) is an evergreen shrub which grows along the eastern coast of Africa and in the Arabian peninsula. Because of their stimulant properties, fresh khat leaves are commonly chewed in these countries [1]. These properties are thought to be due to its main active ingredient, cathinone [2]. Interestingly, khat leaves are also traditionally considered to be a herbal remedy for airway diseases [3, 4], but the mechanism behind this activity is as yet unknown. The current authors have hypothesised that cathinone may contribute to the beneficial effects of khat through modulation of airway neural control.

In the present study, it was hypothesised that cathinone modulates the neural control of airway tone and that this activity may be responsible for some of the beneficial effects seen. Elucidating the mechanism of action of cathinone may lead to the development of new therapeutic entities for the treatment of respiratory diseases.

\section{MATERIALS AND METHODS}

Preparation of human and/or guinea pig tracheal smooth muscle strips and vas deferens Lung tissues were obtained from human healthy donors as previously described [5]. Male DunkinHartley guinea pigs (300-500 g; Harlan, Bicester, UK) were killed by cervical dislocation, and vas deferens and/or tracheal strips were prepared as previously described $[5,6]$.

Contractile/relaxant effects of cathinone per se Cathinone $\left(10^{-9}-10^{-4} \mathrm{M}\right)$ or vehicle $(0.1 \%$ distilled water) was added to the baths with tracheal strips subjected to a resting tension of $1 \mathrm{~g}$, or precontracted with carbachol $\left(10^{-5} \mathrm{M}\right)$.

\section{Contractile responses evoked by exogenous acetylcholine}

Cumulative concentration-response curves to acetylcholine (ACh; $10^{-9}-10^{-3} \mathrm{M}$ ) were compared before and after incubation of the tissues with cathinone or vehicle for $3 \mathrm{~h}$.
AFFILIATIONS

*Respiratory Pharmacology Group, Airway Disease Section, Imperial College, National Heart and Lung Institute, and ${ }^{\#}$ Chelsea and Westminster Hospital, London, UK.

CORRESPONDENCE

M.G. Belvisi

Respiratory Pharmacology

Airway Disease Section

National Heart and Lung Institute Imperial College School of Medicine Guy Scadding Building Dovehouse Street London SW3 6LY UK

Fax: 442073518173

E-mail: m.belvisi@imperial.ac.uk

Received:

December 032007

Accepted after revision:

April 162008

SUPPORT STATEMENT

V.C. Freund-Michel is the recipient of a European Respiratory Society Fellowship (number 154). The authors also thank the Dahdaleh Foundation (St Peter Port, Jersey) for financial support.

STATEMENT OF INTEREST None declared 

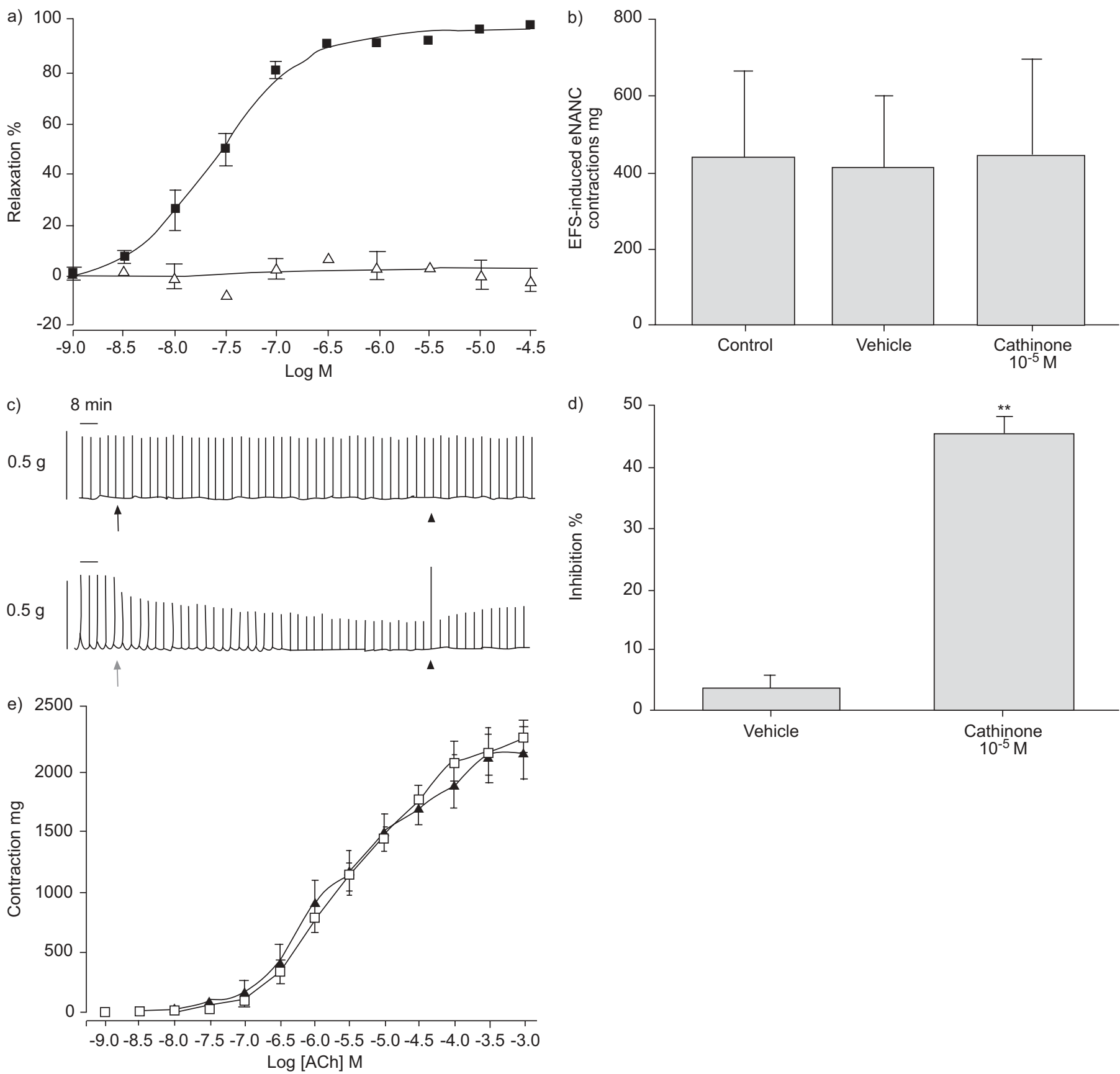

FIGURE 1. Effects of cathinone on the parasympathetic neural control of the airway tone. a) Relaxant effect of cathinone $\left(\triangle ; 10^{-9}-3 \times 10^{-3} \mathrm{M}\right)$ was investigated on guinea pig tracheal smooth muscle strips pre-contracted with the stable muscarinic agonist carbachol $\left(10^{-5} \mathrm{M}\right)$, in the presence of indomethacin (nonselective cyclooxygenase (COX) inhibitor, $\left.10^{-5} \mathrm{M}\right)$. The $\beta_{2}$ adrenergic agonist isoprenaline $\left(\mathbf{\square} ; 10^{-9}-3 \times 10^{-5} \mathrm{M}\right)$ was used as a positive control. Data are expressed as a percentage of relaxation and are presented as mean \pm SEM of three independent experiments. b) Electrically-evoked excitatory nonadrenergic noncholinergic (eNANC) contractions were obtained on preparations of hilar bronchi in presence of indomethacin (nonselective COX inhibitor; $10^{-5} \mathrm{M}$ ), propranolol (nonselective $\beta$-adrenergic antagonist; $10^{-6} \mathrm{M}$ ) and atropine (nonselective muscarinic antagonist, $\left.10^{-6} \mathrm{M}\right)$. eNANC contractions were studied in the presence or absence of cathinone $\left(10^{-5} \mathrm{M}\right)$ or vehicle $(0.1 \%$ distilled water final concentration), incubated to the baths during $20 \mathrm{~min}$. Data are presented as mean \pm SEM and are expressed as absolute values in mg contraction of three independent experiments. EFS: electric field stimulation. c) A representative trace of electric field stimulation-induced contractions of a guinea pig tracheal strip inhibited by cathinone $\left(10^{-5} \mathrm{M}\right.$; grey arrow) is presented, as compared with the effect of the vehicle (black arrow, $0.1 \%$ distilled water final concentration). Arrowheads: wash. d) Electrically-evoked cholinergic contractions were induced in guinea pig tracheal smooth muscle strips (300 mA at source; $0.5 \mathrm{~ms}$ pulse width; $4 \mathrm{~Hz} ; 15 \mathrm{~s}$ every $4 \mathrm{~min}$ ), in the presence of indomethacin (nonselective COX inhibitor; $10^{-5} \mathrm{M}$ ). Cholinergic contractions were studied in the presence or absence of cathinone $\left(10^{-6}-10^{-5} \mathrm{M}\right)$ or vehicle $(0.1 \%$ distilled water final concentration), incubated in the baths until maximal inhibition was observed. Data are presented as mean \pm sEM and are expressed as a percentage of inhibition compared with the control of six independent experiments. Data were analysed by a one-way ANOVA followed by a Dunnett's test. ${ }^{* *}$ : $p<0.01$. e) Exogenous acetylcholine (ACh) dose-response $\left(10^{-9}-10^{-3} \mathrm{M}\right)$ was performed before $(\mathbf{\Lambda})$ and after $(\square)$ cathinone $\left(10^{-5} \mathrm{M}\right)$ pre-incubation $(3 \mathrm{~h})$, in presence of indomethacin $\left(10^{-5} \mathrm{M}\right)$. Data are expressed as absolute values in $\mathrm{mg}$ contraction and are presented as mean \pm SEM of six independent experiments. 


\section{Electric field stimulation-induced contractile responses}

Electric field stimulation (EFS) was elicited as previously described [7]. Cathinone $\left(10^{-6}-3 \times 10^{-5} \mathrm{M}\right)$, nisoxetine $\left(3 \times 10^{-5} \mathrm{M}\right)$ or vehicle was incubated until maximal inhibition was observed. In some experiments, tracheal tissues were preincubated with the $\alpha_{2}$ antagonists yohimbine or idazoxan and/ or the 5-hydroxytryptamine (5-HT)7 antagonist SB269970 for $\geqslant 30 \mathrm{~min}$ before addition of cathinone $\left(10^{-5} \mathrm{M}\right)$. For electrically evoked excitatory nonadrenergic noncholinergic contractions, preparations of hilar bronchi were prepared as previously described [5].

\section{Measurements of $\mathrm{ACh}$ release from tracheal parasympathetic nerves}

The release of ACh from cholinergic nerves was measured as previously described [5].

\section{Expression of results and statistical analysis}

Data are expressed as $\mathrm{mg}$ tension or as percentage change and presented as mean \pm SEM of $n$ independent observations. Parametric data were analysed by an unpaired, two-tailed t-test when comparing two groups, or by a one-way ANOVA followed by a Dunnett's test when comparing several groups to the same control. Nonparametric data were analysed by a Kruskal-Wallis test followed by a Dunn's multiple comparison test. A p-value $<0.05$ was considered statistically significant.

\section{RESULTS}

\section{Contractile/relaxant activity of cathinone per se}

Cathinone had neither contractile activity on guinea pig tracheal smooth muscle strips subjected to a resting tension of $1 \mathrm{~g}$ nor relaxant activity on strips pre-contracted with carbachol $\left(10^{-5} \mathrm{M}\right)$, as compared with the $\beta_{2}$ adrenergic agonist isoprenaline $\left(10^{-9}-10^{-4} \mathrm{M}\right.$; fig. 1a).

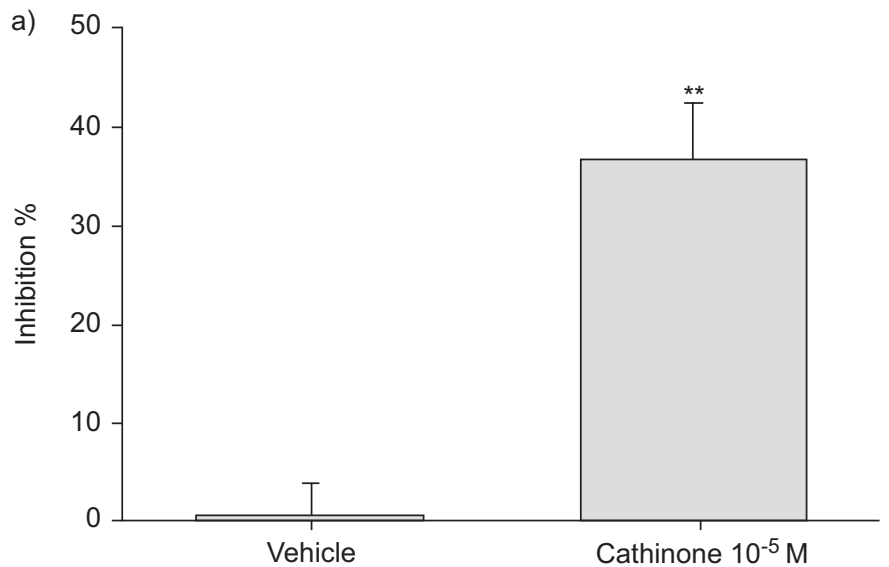

Effect of cathinone on EFS-induced contractile responses EFS-induced nonadrenergic noncholinergic contractions of hilar bronchi were unaffected by cathinone (fig. 1b). EFS induced cholinergic contractions of the tracheal strips were inhibited by cathinone in a concentration-dependent manner (fig. 1c). The maximal inhibition of $44.9 \pm 3.1 \%$ was achieved with cathinone at $10^{-5} \mathrm{M}$ after $138 \pm 11 \mathrm{~min}$ of incubation.

\section{Effect of cathinone on contractile responses evoked by exogenous $\mathrm{ACh}$}

ACh $\left(10^{-9}-10^{-3} \mathrm{M}\right)$ induced contractions of guinea pig tracheal strips in a concentration-dependent manner, which was not modified after pre-incubation $(3 \mathrm{~h}$ ) either with vehicle or with cathinone (fig. 1d).

\section{Effect of cathinone on EFS-induced cholinergic contractions of human tracheal strips}

EFS induced cholinergic contractions of the human tracheal strips that were inhibited by cathinone at $10^{-5} \mathrm{M}(38.4 \pm 5.8 \%$ inhibition; $\mathrm{p}<0.05 ; \mathrm{n}=4$ ) after $92 \pm 15 \mathrm{~min}$ of incubation (fig. 2).

\section{Modulation by cathinone of ACh release by tracheal parasympathetic nerves}

Cathinone $\left(10^{-5} \mathrm{M}\right)$ inhibited EFS-induced ACh release $(26.2 \pm 10.2 \%$ inhibition; $n=4 ; p<0.05$; fig. $3 a$ and $b)$. The nonselective muscarinic agonist oxotremorine $\mathrm{M}\left(10^{-6} \mathrm{M}\right)$, used as a positive control [8], induced a $72.3 \pm 6.2 \%$ inhibition of EFS-induced $\left[{ }^{3} \mathrm{H}\right] \mathrm{ACh}$ release from guinea pig tracheal strips $(\mathrm{n}=4 ; \mathrm{p}<0.01)$.

\section{Modulation of guinea pig vas deferens contractile responses induced by EFS}

One possible mechanism of action for cathinone is on the airway sympathetic innervation. The effect of cathinone on the vas deferens, a tissue with a "classical" sympathetic innervation, was studied. Incubation with nisoxetine, an inhibitor of the

b)
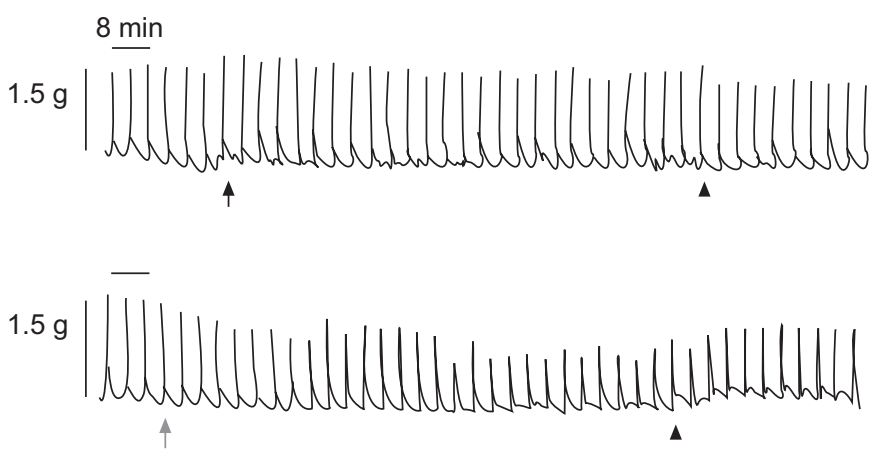

FIGURE 2. Effect of cathinone on electric field stimulation-induced contractions of human tracheal strips. a) Electrically-evoked cholinergic contractions were induced in

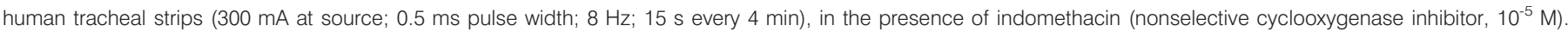

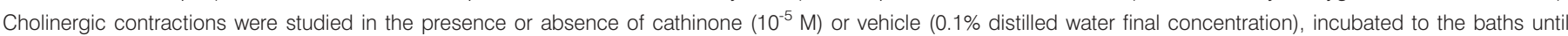

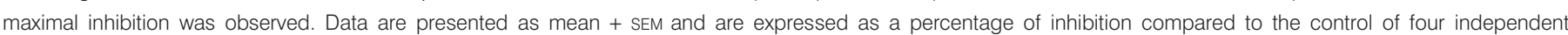

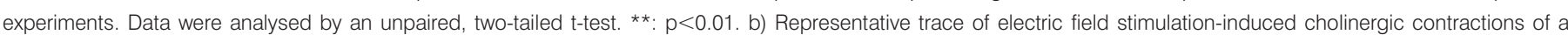

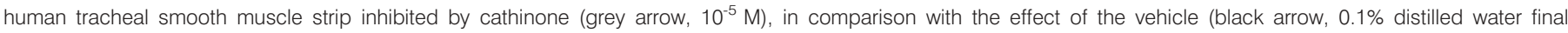
concentration). Arrowhead: wash 

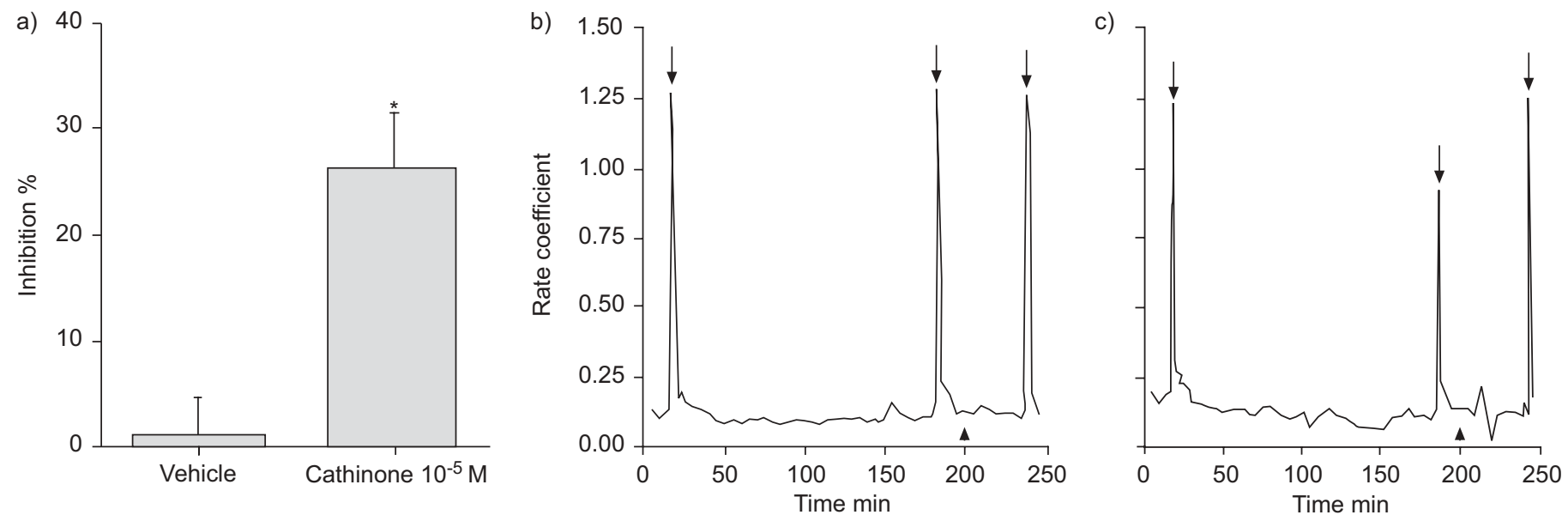

FIGURE 3. Inhibition by cathinone of acetylcholine (ACh) release from parasympathetic nerves innervating the guinea pig trachea. a) Effect of cathinone (10 $\left.0^{-5} \mathrm{M}\right)$ on electric field stimulation (EFS)-induced $\left[{ }^{3} \mathrm{H}\right] \mathrm{ACh}$ release from guinea pig tracheal strips. Each tissue acted as its own control such that the data presented reflect the percentage change in EFS-induced $\left[{ }^{3} \mathrm{H}\right]$ ACh output after drug administration, relative to the first control stimulation. Data are presented as mean + SEM of four independent experiments. Data were analysed by an unpaired, two-tailed t-test for paired data. ${ }^{*}: p<0.05$. Representative data of the inhibition of EFS-induced [ $\left.{ }^{3} \mathrm{H}\right] \mathrm{ACh}$ release from an individual guinea-pig tracheal strip by b) vehicle (distilled water, $0.1 \%$ final concentration) or c) cathinone $\left(10^{-5} \mathrm{M}\right)$. Each point represents the rate coefficient of ACh output, which is a measure of the fractional quantity of tritium released per unit time: Arrows: EFS stimulation; arrowhead: washout.

noradrenaline transporter $\left(10^{-9}-10^{-4} \mathrm{M}\right)$ induced a concentrationdependent increase in the EFS-induced contractions of the guinea pig vas deferens, with a maximal increase of $54.9 \pm 3.2 \%$ at $3 \times 10^{-5} \mathrm{M}$ after $34 \pm 10 \mathrm{~min}$ of incubation. Incubation with cathinone induced a concentration-dependent inhibition of EFS-induced contractions of the guinea pig vas deferens, with a maximal inhibition of $55.8 \pm 6.5 \%$ at $10^{-5} \mathrm{M}$ after $46 \pm 9 \mathrm{~min}$ of incubation (fig. 4), suggesting that the mechanism of action is not via inhibition of the noradrenaline transporter.

\section{Effects of $\alpha_{2}$ adrenergic and 5-HT7 antagonists}

The effect of cathinone on EFS-induced cholinergic contractions of guinea pig tracheal smooth muscle strips was reversed

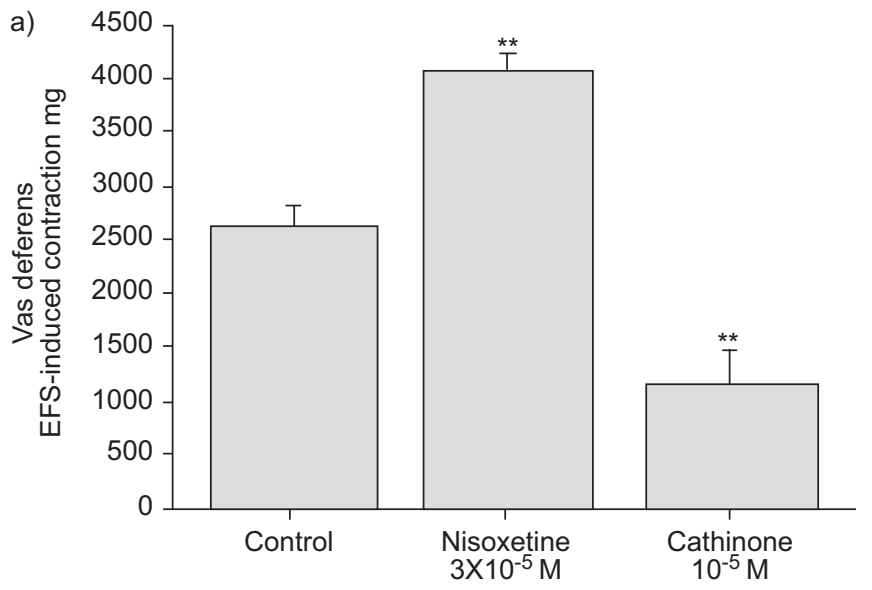

by the selective $\alpha_{2}$ adrenergic antagonist yohimbine or by the selective 5-HT7 antagonist SB269970. The effect of yohimbine was confirmed by use of idazoxan, another $\alpha_{2}$ adrenergic antagonist $\left(10^{-5} \mathrm{M} ; 51.3 \pm 1.6 \%\right.$ inhibition; $\left.\mathrm{n}=6 ; \mathrm{p}<0.01\right)$. A combination of these two antagonists further inhibited the effect of cathinone $(n=6 ; p<0.001$; fig. 5a). On human tracheal smooth muscle strips, the effect of cathinone was inhibited in a similar manner by yohimbine or by SB269970 (fig. 5b), and a combination of these two antagonists totally inhibited the effect of cathinone. No effect of yohimbine and/or SB269970 was observed per se on EFS-induced cholinergic contractions of neither guinea pig nor human tracheal smooth muscle strips. The lack of effect of yohimbine on EFS-induced cholinergic

b) $4 \mathrm{~min}$

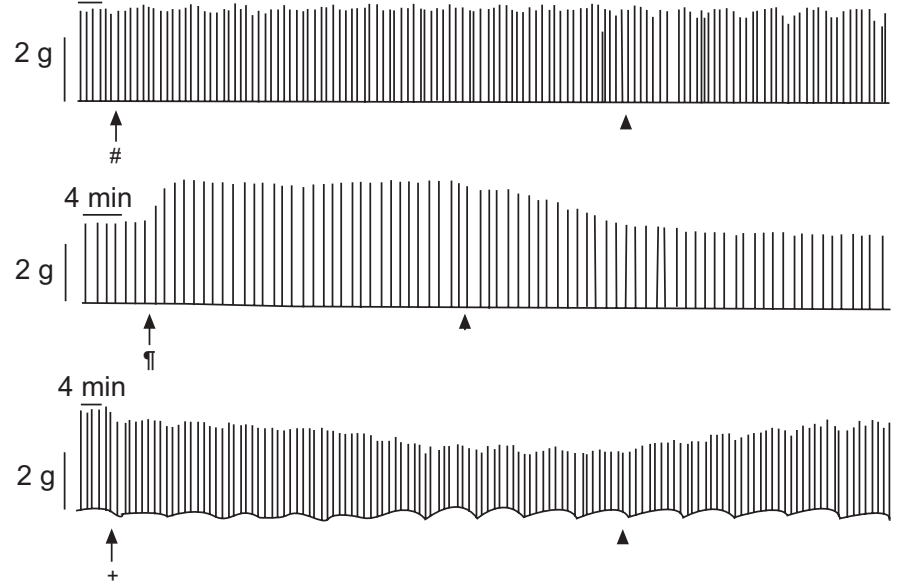

FIGURE 4. Effect of cathinone on electric field stimulation (EFS)-induced contractions of the guinea pigs vas deferens. a) Electrically-evoked contractions were induced in guinea pig vas deferens portions (300 mA at source, $1 \mathrm{~ms}$ pulse width, $20 \mathrm{~Hz}, 1 \mathrm{~s}$ every min), in the presence of indomethacin (nonselective cyclooxygenase inhibitor, $10^{-5} \mathrm{M}$ ). Contractions were studied in the presence or absence of nisoxetine (inhibitor of the noradrenaline transporter; $3 \times 10^{-5} \mathrm{M}$ ), cathinone $\left(10^{-5} \mathrm{M}\right)$ or vehicle (distilled water, $0.1 \%$ final concentration), incubated to the baths until maximal inhibition was observed. Data are presented as mean \pm SEM and are expressed as absolute values in mg contraction of six independent experiments. Data were analysed by a one-way ANOVA followed by a Dunnett's test. $* *: p<0.01$. b) Representative traces of EFS-induced contractions of the guinea pig vas deferens potentiated by nisoxetine $\left(3 \times 10^{-5} \mathrm{M} ;{ }^{\circ}\right)$ or inhibited by cathinone $\left(10^{-5} \mathrm{M} ;^{+}\right)$as compared to the effect of the vehicle $\left({ }^{*}\right)$. Arrowhead: wash. 

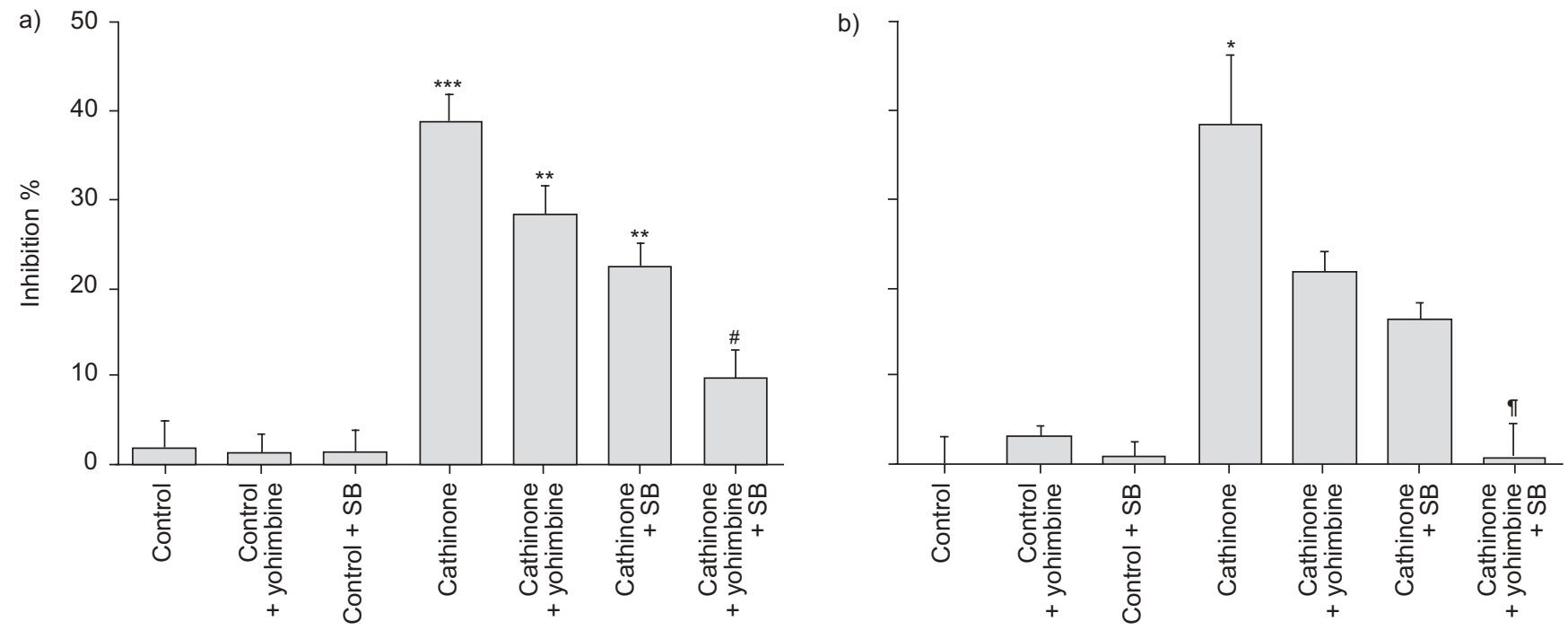

FIGURE 5. Effect of the $\alpha_{2}$ and/or 5-hydroxytryptamine (5-HT)7 antagonists on the effect of cathinone. Electric field stimulation-induced contractions were induced in a) guinea pig or b) human tracheal smooth muscle strips. The effect of cathinone $\left(10^{-5} \mathrm{M}\right)$ was assessed in presence or absence of yohimbine $\left(\alpha_{2}\right.$ adrenergic selective antagonist; $10^{-5} \mathrm{M}$ ) and/or SB269970 (5-HT7 selective antagonist; $10^{-5} \mathrm{M}$ ). Both antagonists were incubated 30 min with tissues before adding cathinone, and indomethacin (nonselective cyclooxygenase inhibitor; $10^{-5} \mathrm{M}$ ) was present throughout the experiment. Data are presented as mean + SEM and are expressed as a percentage of inhibition compared to the control of six and three independent experiments in guinea pig and human tracheal smooth muscle strips, respectively. Data were analysed by KruskalWallis test followed by a Dunn's multiple comparison test. ${ }^{*}$ : $p<0.05$; ${ }^{* \star *}: p<0.001$, compared with controls. ${ }^{* *}: p<0.01 ;{ }^{*}: p<0.001 ;{ }^{\natural}: p<0.05$, compared with cathinone.

contractions in guinea pig trachea is consistent with previous data from STRETTON and BARNES [9].

\section{DISCUSSION}

Cathinone has been demonstrated to be the main active constituent in fresh khat leaves [10] and increases the release of catecholamines in the brain and, as such, is thought to be responsible for the stimulant effect obtained by chewing khat [11]. A number of studies have shown that cathinone also affects the peripheral nervous system $[12,6]$. The present finding, that cathinone targets the airways, is, therefore, in accordance with these other reported peripheral actions of cathinone.

The aim of the present study was to determine whether cathinone had any beneficial activity on airway tone that may contribute to the beneficial properties of khat, as reported as a result of its use as a traditional African remedy for the treatment of airway diseases. The current authors report, for the first time, that this natural product modulates the cholinergic control of the tracheal smooth muscle through concomitant activation of $\alpha_{2}$ adrenergic and 5-HT7 presynaptic
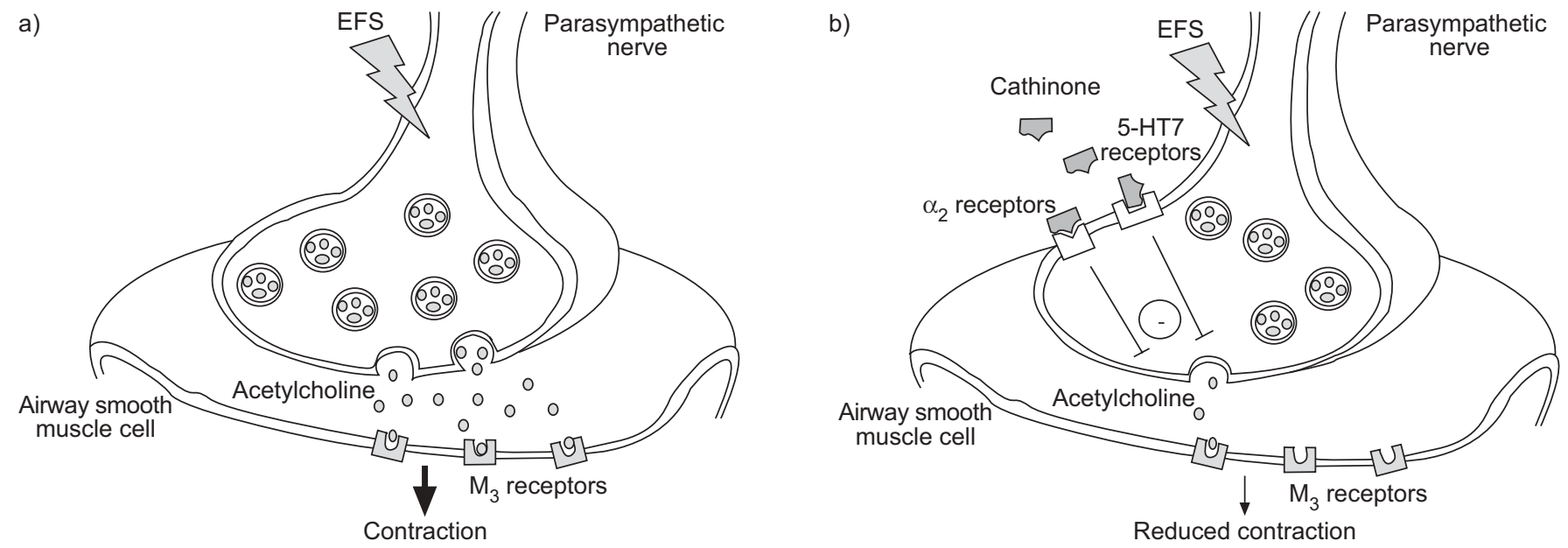

FIGURE 6. Schematic representation of the effects of cathinone on parasympathetic nerves innervating the tracheal smooth muscle. a) Electrical field stimulation (EFS) induces acetylcholine release from parasympathetic nerves innervating the tracheal smooth muscle, which activates its postsynaptic $\mathrm{M}_{3}$ muscarinic receptors and induces contractions of the airway smooth muscle. b) In the presence of cathinone, presynaptic $\alpha_{2}$ adrenergic and 5-hydroxytryptamine (5-HI) receptors are activated and inhibit EFSinduced acetylcholine release from airway parasympathetic nerves, therefore reducing acetylcholine-induced contractions of the airway smooth muscle through reduced postsynaptic muscarinic $M_{3}$ receptors activation. 
receptors and inhibition of $\mathrm{ACh}$ release from parasympathetic nerves innervating the airways (fig. 6).

The current study is the first to show that cathinone acts presynaptically to inhibit cholinergic contractions of the tracheal smooth muscle. Cathinone has been previously shown to induce its central [11] and some of its peripheral $[13,14]$ effects mainly via a sympathomimetic mechanism. Therefore, the current authors investigated the effect of cathinone on the vas deferens, a "classical" sympathetic system. In this organ, EFS-induced contractions are mainly due to the release of noradrenaline from presynaptic stores and activation of postsynaptic $\alpha_{1}$ adrenergic receptors [15]. A sympathomimetic effect in this system would result in increased EFS-induced contractions, as exemplified in the present experiments using nisoxetine, an inhibitor of the noradrenaline transporter. In contrast, cathinone inhibited EFS-induced contractions of the guinea pig vas deferens. This is consistent with other recent studies demonstrating sympathomimetic-independent effects of cathinone [16].

Interestingly, a previous study has reported that cathinone only exhibited affinity for two receptors: $\alpha_{2}$ adrenergic and 5-HT7 receptors when screened against a large battery of cloned human receptors and transporters [17]. Interestingly, the existence of presynaptic $\alpha_{2}$ adrenergic and 5-HT7 receptors has previously been suggested on parasympathetic nerves innervating the trachea, with their activation reducing EFSinduced contractions through inhibition of ACh release [18, 19]. However, functional effects of cathinone via activation of these receptors have never been reported. Therefore this was investigated as a possible mechanism, and it was shown that the inhibitory effect of cathinone was inhibited in human tissues by a combination of $\alpha_{2}$ and 5-HT7 antagonists.

In conclusion, the present study shows for the first time that cathinone presynaptically inhibits acetylcholine release from airway parasympathetic nerves through activation of both $\alpha_{2}$ and 5-hydoxytryptamine 7 presynaptic receptors. This effect may contribute to the beneficial effects of khat that have been traditionally reported in airway diseases [3, 4]. In addition, the dual mechanism of action revealed for cathinone in the present study may be particularly beneficial in airway diseases displaying a heightened cholinergic tone, such as asthma associated with gastro-oesophageal reflux [13], nocturnal asthma [14] or chronic obstructive pulmonary disease [20]. The development of new anticholinergic molecules based on mechanisms of action other than antagonising muscarinic receptors may be particularly interesting in the treatment of such airway diseases with heightened cholinergic tone.

\section{ACKNOWLEDGEMENTS}

The authors thank S. Haj-Yahia (Royal Brompton and Harefield Hospital, London UK) for help with the provision of human tissue samples.

\section{REFERENCES}

1 Drake PH. Khat-chewing in the Near East. Lancet 1988; 1: 532-533.

2 Szendrei K. The chemistry of khat. Bull Narc 1980; 32: 5-35.
3 Al-Meshal IA, Ageel AM, Parmar NS, Tariq M. Catha edulis (khat): use, abuse and current status of scientific knowledge. Fitoterapia 1985; 56: 131-152.

4 Watt JM, Breyer-Brandwijk MG. The Medicinal and Poisonous Plants of Southern and Eastern Africa. 2nd Edn. London, E. and S. Livingstone, 1932.

5 Patel HJ, Barnes PJ, Takahashi T, Tadjkarimi S, Yacoub MH, Belvisi MG. Evidence for prejunctional muscarinic autoreceptors in human and guinea pig trachea. Am J Respir Crit Care Med 1995; 152: 872-878.

6 Hassan NA, Gunaid AA, El Khally FM, Murray-Lyon IM. The subjective effects of chewing Qat leaves in human volunteers. Ann Saudi Med 2002; 22: 34-37.

7 Belvisi MG, Patel HJ, Takahashi T, Barnes PJ, Giembycz MA. Paradoxical facilitation of acetylcholine release from parasympathetic nerves innervating guinea pig trachea by isoprenaline. Br J Pharmacol 1996; 117: 1413-1420.

8 Patel HJ, Giembycz MA, Keeling JE, Barnes PJ, Belvisi MG. Inhibition of cholinergic neurotransmission in guinea pig trachea by NS1619, a putative activator of large-conductance, calcium-activated potassium channels. J Pharmacol Exp Ther 1998; 286: 952-958.

9 Stretton CD, Barnes PJ. Modulation of cholinergic neurostransmission in guinea-pig trachea by neuropeptide $\mathrm{Y}$. Br J Pharmacol 1988; 93: 672-678.

10 Al-Motarreb A, Baker K, Broadley KJ. Khat: pharmacological and medical aspects and its social use in Yemen. Phytother Res 2002; 16: 403-413.

11 Kalix P. Pharmacological properties of the stimulant khat. Pharmacol Ther 1990; 48: 397-416.

12 Al-Motarreb A, Al-Kebsi M, Al-Adhi B, Broadley KJ. Khat chewing and acute myocardial infarction. Heart 2002; 87: 279-280.

13 Harding SM. Gastroesophageal reflux and asthma: insight into the association. J Allergy Clin Immunol 1999; 104: 251-259.

14 Morrison JF, Pearson SB, Dean HG. Parasympathetic nervous system in nocturnal asthma. Br Med J (Clin Res Ed) 1988; 296: 1427-1429.

15 Westfall TD, Westfall DP. Pharmacological techniques for the in vitro study of the vas deferens. J Pharmacol Toxicol Methods 2001; 45: 109-122.

16 Al-Motarreb AL, Broadley KJ. Coronary and aortic vasoconstriction by cathinone, the active constituent of khat. Auton Autacoid Pharmacol 2003; 23: 319-326.

17 Rothman RB, Vu N, Partilla JS, et al. In vitro characterization of ephedrine-related stereoisomers at biogenic amine transporters and the receptorome reveals selective actions as norepinephrine transporter substrates. J Pharmacol Exp Ther 2003; 307: 138-145.

18 Kamikawa Y, Shimo Y. Inhibitory effects of sympathomimetic drugs on cholinergically mediated contractions of guinea-pig isolated tracheal muscle. J Pharm Pharmacol 1986; 38: 742-747.

19 Dupont LJ, Pype JL, Demedts MG, De Leyn P, Deneffe G, Verleden GM. The effects of 8-hydroxy-2-(di-n-propylamino)tetralin on the cholinergic contraction in guinea pig and human airways in vitro. Am J Respir Crit Care Med 1998; 158: 1479-1486.

20 Undem BJ, Kollarik M. The role of vagal afferent nerves in chronic obstructive pulmonary disease. Proc Am Thorac Soc 2005; 2: 355-360. 